\title{
Editorial.
}

\section{New year, new phase for QOE-IJES}

With the current issue, the first of 2020, Quaderni dell'Osservatorio Elettorale - Italian Journal of Electoral Studies enters a new stage of its long life as a journal devoted to publishing high-quality articles in the field of election studies. This forty-third birthday signals many changes: with its new Italian-English name and acronym, QOE-IJEL becomes the official journal of the Italian Society for Electoral Studies (SISE - Società Italiana di Studi Elettorali), appoints new editors and editorial team, and migrates to a new publisher.

QOE was born in October 1977, when the first issue appeared as a bi-annual journal edited on the initiative of the Study Group on Electoral Behavior set up at the Council of the Region Tuscany.

In 1980 Mario Caciagli, since the very beginning in the founding Study Group and the Editorial Staff, took the lead of the journal and passionately edited it for four long decades. In the early times, QOE primarily spoke to the Italian social science community interested in electoral issues; over the years, Caciagli has expanded the journal both in the variety of high-quality papers published and intending to reach a global readership. Under his editorship, the journal achieved high standards, a multi-disciplinary vision, and a consolidated international reputation.

A second phase in the life of the journal began in 2015, always under Mario Caciagli's firm wrist: the journal renewed its Editorial Staff and faced the challenge of the contemporary international standards.

With this issue, a third phase begins. It is therefore with great privilege that we are taking over as Editors. The SISE supports our editorial efforts to broaden our international audience, in terms of both readers and contributors. To achieve this, the journal is published in English - although articles in Italian are most welcome - at Firenze University Press, a young and dynamic publishing house, which allows wide dissemination of our articles. Moreover, to support the international scope of the journal, we have been so fortunate to have many dis- tinguished international scholars to sit in our advisory board. The new editorial board will be in charge for the next four years. This editorial transition will be regular in the future to ensure that QOE-IJES can reinvent itself and thereby adjust to the changing times.

Our aim as editors is to continue publishing highquality original papers from both Italian and international scholars to further becoming a major outlet of elections and voting, public opinion, political behavior, and party studies in Italy and beyond.

QOE-IJES embraces all approaches to electoral research, without restriction to any particular theory, method, topic or geographical scope. Articles will seek to engage with current debates and disciplinary developments, whether theoretical or empirical. Within broad topics concerning democracy and its new challenges like e-voting, big and open (electoral) data, citizenship and elections - contributions are welcome from all perspectives. These may cover aspects such as turnout, voting behavior, public opinion, campaigns, political parties, and electoral systems, amongst many others. The journal is a political science review, but it is traditionally open to scholars working in any of the major social science disciplines such as political economy, sociology, contemporary history, social policy, social anthropology, socio-legal studies.

Our first 2020 issue is an excellent example of the blend of research we aim to publish. The reader is offered analyses of the politics of electoral reform in Italy (Alessandro Chiaramonte), of political participation at the local level in Europe (João Cancela), of the predictive power of polls in the US (Jackson, Lewis-Beck and Tien), of the representative deficit in different EU countries (Bright, Garzia, Lacey, and Trechsel), and of the impact of media on political (dis)trust in Europe (Vincenzo Memoli).

It remains then for us to thank those others who have had made all the successes of the last decades possible: along with our founding editor Mario Caciagli, 
who promoted these many changes and supported our renewed mission, we wish to thank the long-serving Managing Editor, Carlo Baccetti; the Editorial staff (Lorenzo De Sio, Stefano Rombi, and Antonio Floridia); the Osservatorio della Regione Toscana, which hosted the journal on its website; the Giunta regionale, which produced and disseminated the journal thus far. We gratefully acknowledge the still present support of the Regione Toscana, whose financial contribution makes our open-access journal possible. We also want to thank the authors and reviewers of the political and social sciences scientific community, without whom the QOE would not exist.

Last but of course not least, our thank goes to the SISE President, Fulvio Venturino, who enthusiastically supported this renewal, and to the SISE Scientific Committee for having selected us as the new editors. We hope to be able to meet the expectations that Mario and SISE share for the future of the journal.

Paolo Bellucci Silvia Bolgherini 